\title{
Surgical outcomes of endoscopic versus open resection for the management of sinonasal malignancies
}

\author{
Balamurugan Rajendran \\ Oral and Maxillofacial Surgeon and Oral Implantologist, RYA Cosmo Foundation, Chennai, India
}

\begin{abstract}
J Korean Assoc Oral Maxillofac Surg 2020;46:373-378)
The purpose of this review is to assess the surgical outcomes of two different treatment modalities, endoscopic and open resection, for the management of sinonasal malignancies by comparing the effectiveness of these two methods. A wide search was carried out considering various electronic databases for English language articles from 2013 to 2018 using keywords such as sinonasal malignancies, endoscopic surgery, open resection for sinonasal malignancies, and endoscopic versus open surgery. One thousand articles were identified from the literature for screening. After a thorough systematic assessment and based on the selection criteria, 10 articles with 4,642 patients were included in this quantitative analysis. With a total of 4,642 patients, 1,730 patients were operated on using endoscopic resection and 2,912 patients were operated on using open resection. The endoscopic approach was found to have a shorter hospital stay compared to open surgical resection $(P<0.05)$. The rate of positive margins and the recurrence rate for open surgical resection were both smaller compared to those for endoscopic resection $(P>0.05)$, and the endoscopic approach had smaller complication rates and a higher survival rate compared to open resection $(P>0.05)$. Though endoscopic resection and open surgical resection have comparable postoperative benefits, preoperative evaluation of cases presenting with sinonasal malignancies is necessary for determining the right treatment method to obtain the best possible results postoperatively.
\end{abstract}

Key words: Sinonasal malignancy, Endoscopic approach, Open resection

[paper submitted 2020. 5. 23 / revised 1st 2020. 8. 31, 2nd 2020. 9. 13 / accepted 2020. 10. 5]

\section{Introduction}

Malignant tumors involving sinonasal region are rare, comprising only $3 \%$ of head and neck cancers ${ }^{1}$. The most preferred sites of occurrence for these tumors are the nasal cavity followed by the maxillary sinus and ethmoid sinuse ${ }^{2,3}$. Squamous cell carcinoma (SCC) is the most common histologic diagnosis ${ }^{4,5}$. Sinonasal malignancies have a poor prognosis, and the 5 -year survival rate was only $30 \%$ to $59 \%{ }^{6,7}$. Two treatment modalities are practiced in routine basis: open resection via the craniofacial approach, which is a standard method employed for the management of sinonasal tumors;

\section{Balamurugan Rajendran}

Oral and Maxillofacial Surgeon and Oral Implantologist, RYA Cosmo Foundation, 380 Konnur High Road, Otteri, Chennai 600012, Tamilnadu, India TEL: +91-44-26620219

E-mail: bala100192@gmail.com

ORCID: https://orcid.org/0000-0002-9288-6448

(c) This is an open-access article distributed under the terms of the Creative Commons Attribution Non-Commercial License (http://creativecommons.org/ licenses/by-nc/4.0/), which permits unrestricted non-commercial use, distribution, and reproduction in any medium, provided the original work is properly cited.

Copyright (C) 2020 The Korean Association of Oral and Maxillofacial Surgeons. All rights reserved. and endoscopic resection, which is a recent method compared to open surgical resection.

Open surgical resection provides wider access and better visibility with high rates of complete resection ${ }^{8,9}$. However, open resection offers high rates of complications that can occur immediately following surgery, in a delayed fashion with an infection rate up to $18 \%$ at the surgical site, as a complication of the central nervous system with rates up to $15 \%$, or even as complications that lead to postoperative mortality with rates up to $4.5 \%{ }^{10,11}$. Endoscopic resection is a minimally invasive procedure with better cosmesis, and complete resection of the tumor can be ensured, similar to open resection, while ensuring long term survival rates with minimal complications $^{12,13}$.

The purpose of this paper is to compare the surgical outcomes of two different approaches, namely endoscopic resection and open resection, in terms of the positive margins. We compare these two methods by considering their complication rates, length of hospital stay, recurrence rate and the overall survival rate in the management of sinonasal malignancies. 


\section{Materials and Methods}

\section{Search strategy}

This present systematic review was carried out based on the PRISMA (Preferred Reporting Items for Systematic Reviews and Meta-Analyses). A Literature search was performed for various electronic databases such as the PubMed, Scopus, ScienceDirect, Google Scholar, and Cochrane Library databases from 2013 to 2018 using the key words sinonasal malignancies, endoscopic surgery, and open resection for sinonasal malignancies. All the articles were assessed based on multiple inclusion and exclusion criteria.

\section{Selection criteria}

The articles included in the present review were clinical trials with comparative treatment modalities: endoscopic resection and open surgery, histopathology of malignancies involving sinonasal cavity, articles reported with one surgical approach, and age $>20$ years. The surgical outcomes measured include the complication rate, positive margins, rate of recurrence, length of hospital stay, and histologic subtypes. Exclusion criteria were histologic representation of mucosal melanoma since they dictate the type of tumor, case series and case reports, cranio-endoscopic approaches, recurrent pathologies of sinonasal cavity, and cases that received preoperative chemotherapy or radiotherapy.

\section{Results}

\section{Literature search}

A wide search through the English literature yielded 1,000 studies. After removal of 478 duplicates, inclusion and exclusion criteria were applied for 522 studies. Of the articles, 496 articles were excluded (cranio-endoscopic approaches, preoperative exposure to chemotherapy or radiotherapy, not in the sinonasal region, and case reports/case series) and 26 articles were included in the full text analysis. Among the 26 articles, 16 were excluded due to the following reasons: 6 mucosal melanoma cases, 4 recurrent histologies, 3 hybrid surgeries, and 3 articles with no appropriate data. Finally, 10 articles comprising 4,642 patients were considered for quantitative analysis.(Fig. 1)

\section{Demographics and clinical features}

In the present review, a total of 4,642 patients were included with a mean age ranging from 38 to 75 years and $40 \%$
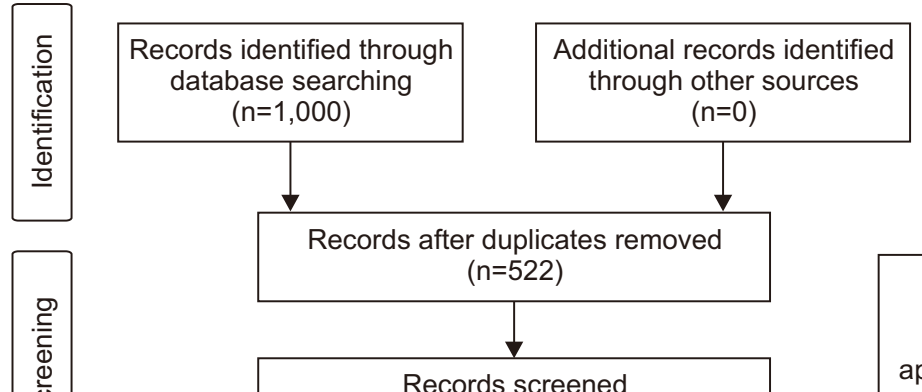

Records excluded $(n=496)$

Craniendoscopic approaches, preoperative exposure to chemotherapy or radiotherapy, not in sinonasal region, case
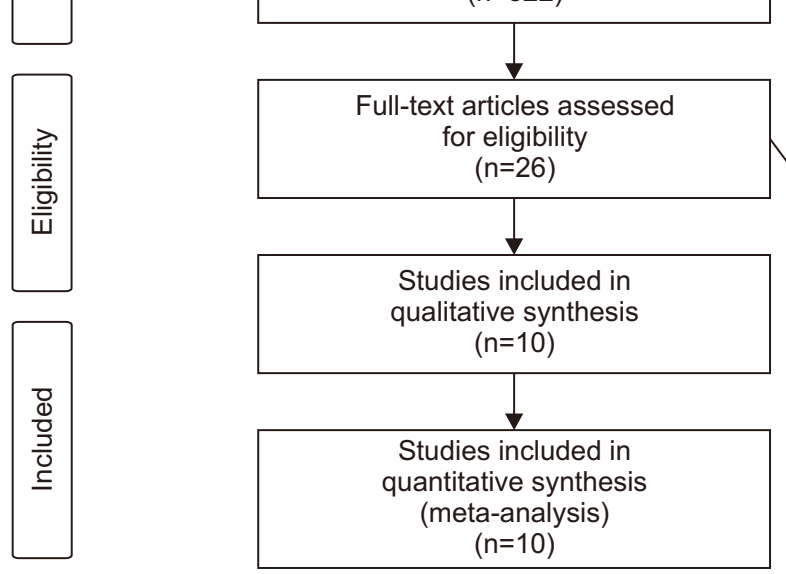

reports/case series

Full-text articles excluded with reasons $(n=16)$

6 mucosal melanoma

4 recurrent histologies

3 hybrid surgeries

3 no appropriate data
Fig. 1. PRISMA (Preferred Reporting Items for Systematic Reviews and Meta-Analyses) search strategy. Balamurugan Rajendran: Surgical outcomes of endoscopic versus open resection for the management of sinonasal malignancies. J Korean Assoc Oral Maxillofac Surg 2020 
to $98 \%$ were male. Of the patients, 1,730 patients underwent endoscopic resection and 2,912 patients underwent open surgical resection with a mean follow-up of 20 to 76 months. For numerous sinonasal malignancies, SCC was the most common occurrence.(Table 1)

\section{Positive margins}

Arnold et al. ${ }^{14}$ observed $68 \%$ positive margins in endoscopic resection and $62 \%$ in open resection $(P=0.636)$. Farquhar et al. ${ }^{15}$ observed $33 \%$ positive margins in endoscopic resection and $32 \%$ in open resection $(P=0.708)$. Finally, Hagemann et al. ${ }^{16}$ observed positive margins of $22 \%$ and $24 \%$ in endoscopic resection and open resection $(P=0.080)$, respectively.(Table 2 )

\section{Length of hospital stay}

Farquhar et al. ${ }^{15}$ observed 3 days of hospital stay for the endoscopic approach and 6 days for the open resection approach $(P=0.0001)$. Hagemann et al. ${ }^{16}$ identified 6 days of hospital stay with endoscopic resection and 9 days with open resection $(P=0.001)$. Mortuaire et al. ${ }^{17}$ observed 5 days of hospital stay with the endoscopic approach and 8 days with the open resection approach $(P=0.001)$. Similarly, Fu et al. ${ }^{18}$ also identified a shorter length of hospital stay for endoscopic resection than for open surgical resection of 6 days and 12 days $(P=0.01)$, respectively.(Table 2$)$

\section{Complication rates}

Naunheim et al. ${ }^{12}$ reported 1 case of cerebrospinal fluid (CSF) leak in endoscopic resection and 12 wound infections, 3 meningitis cases, and $2 \mathrm{CSF}$ leaks in the open resection $(P=0.75)$. Arnold et al. ${ }^{14}$ described 5 complications: 2 CSF leaks, 2 local bleeding, and 1 case of pneumocephalon with open resection; however, they observed no complications with endoscopic resection $(P=0.396)$. Hagemann et al. ${ }^{16}$ observed 1 patient CSF leak in endoscopic resection and 8 patients with open surgical resection $(P=0.54)$. Mortuaire et al. ${ }^{17}$ observed complications in 2 patients ( 1 hematoma and 1 wound infection) in open resection and no complications in endoscopic resection $(P=0.80)$. Fu et al. ${ }^{18}$ highlighted the occurrence of 2 patients CSF leak in endoscopic resection and 1

Table 2. Surgical outcome variables for endoscopic and open resection

\begin{tabular}{|c|c|c|c|}
\hline Outcome variables & $\begin{array}{l}\text { Endoscopic } \\
\text { resection }\end{array}$ & $\begin{array}{l}\text { Open } \\
\text { resection }\end{array}$ & $P$-value \\
\hline \multicolumn{4}{|l|}{ Positive margins (\%) } \\
\hline Arnold et $\mathrm{al}^{14}$ & 68 & 62 & 0.636 \\
\hline Farquhar et al. ${ }^{15}$ & 33 & 32 & 0.708 \\
\hline Hagemann et al. ${ }^{16}$ & 22 & 24 & 0.080 \\
\hline \multicolumn{4}{|c|}{ Length of hospital stay (day) } \\
\hline Farquhar et al. ${ }^{15}$ & 3 & 6 & $0.0001 *$ \\
\hline Hagemann et al. ${ }^{16}$ & 6 & 9 & $0.001 *$ \\
\hline Mortuaire et al. ${ }^{17}$ & 5 & 8 & $0.001 *$ \\
\hline Fu et al. ${ }^{18}$ & 6 & 12 & $0.01^{*}$ \\
\hline \multicolumn{4}{|l|}{ Complication rate (n) } \\
\hline Naunheim et al. ${ }^{12}$ & 1 & 17 & 0.75 \\
\hline Arnold et al. ${ }^{14}$ & 0 & 5 & 0.396 \\
\hline Hagemann et al. ${ }^{16}$ & 1 & 8 & 0.54 \\
\hline Mortuaire et al. ${ }^{17}$ & 0 & 2 & 0.80 \\
\hline Fu et al. ${ }^{18}$ & 2 & 1 & 0.20 \\
\hline \multicolumn{4}{|l|}{ Recurrence rate (n) } \\
\hline Farquhar et al..$^{15}$ & 16 & 13 & 0.058 \\
\hline Hagemann et al. ${ }^{16}$ & 57 & 52 & 0.490 \\
\hline Fu et al. ${ }^{18}$ & 14 & 7 & 0.21 \\
\hline Saedi et al. ${ }^{19}$ & 59 & 58 & 0.168 \\
\hline Huang et al. ${ }^{20}$ & 66 & 66 & 0.359 \\
\hline \multicolumn{4}{|l|}{ Overall survival rate $(\%)$} \\
\hline Naunheim et al. ${ }^{12}$ & 5 yr: 41 & 5 yr: 41 & 0.14 \\
\hline Farquhar et al. ${ }^{15}$ & 3 yr: 91 & 3 yr: 76 & 0.135 \\
\hline Hagemann et al. ${ }^{16}$ & 5 yr: 76 & 5 yr: 59 & $0.001 *$ \\
\hline Saedi et al. ${ }^{19}$ & 2 yr: 34 & 2 yr: 44 & 0.13 \\
\hline
\end{tabular}

$* P<0.05$.

Balamurugan Rajendran: Surgical outcomes of endoscopic versus open resection for the management of sinonasal malignancies. J Korean Assoc Oral Maxillofac Surg 2020

Table 1. Demographics of the included study

\begin{tabular}{|c|c|c|c|c|c|c|c|c|}
\hline Study & $\begin{array}{l}\text { Study } \\
\text { type }\end{array}$ & Malignancy & $\begin{array}{c}\text { Total } \\
\text { size }(n)\end{array}$ & $\begin{array}{l}\text { Endoscopic } \\
\text { resection }(n)\end{array}$ & $\begin{array}{c}\text { Open } \\
\text { resection }(n)\end{array}$ & $\begin{array}{c}\text { Mean } \\
\text { age (yr) }\end{array}$ & $\begin{array}{c}\operatorname{Sex} \\
(\mathrm{M} / \mathrm{F}) \\
(\%)\end{array}$ & $\begin{array}{l}\text { Mean } \\
\text { follow-up } \\
\quad(\mathrm{mo})\end{array}$ \\
\hline Kilic et al. $^{4}$ & $\mathrm{RCT}$ & $\mathrm{SCC}$ & 1,483 & 353 & 1,130 & 35 & $65 / 35$ & 60 \\
\hline Naunheim et al. $^{12}$ & RCT & SCC & 55 & 10 & 45 & 58 & $69 / 31$ & 27.4 \\
\hline Arnold et al. ${ }^{14}$ & $\mathrm{RCT}$ & $\mathrm{SCC}$ & 900 & 399 & 501 & 63 & $67 / 33$ & 36.3 \\
\hline Farquhar et al. ${ }^{15}$ & $\mathrm{RCT}$ & SCC & 124 & 82 & 42 & 54 & $53 / 47$ & 40 \\
\hline Hagemann et al. ${ }^{16}$ & $\mathrm{RCT}$ & $\mathrm{SCC}$ & 225 & 123 & 102 & 63 & $60 / 40$ & 45.4 \\
\hline Mortuaire et al. ${ }^{17}$ & RCT & Adenocarcinoma & 43 & 20 & 23 & 70 & $98 / 2$ & 79.2 \\
\hline Fu et al. ${ }^{18}$ & RCT & $\mathrm{SCC}$ & 87 & 15 & 72 & 57 & $57 / 43$ & - \\
\hline Saedi et al. ${ }^{19}$ & RCT & $\mathrm{SCC}$ & 83 & 28 & 55 & 46 & $70 / 30$ & 21 \\
\hline Huang et al. ${ }^{20}$ & $\mathrm{RCT}$ & SCC & 47 & 27 & 20 & 58 & $60 / 40$ & 73.6 \\
\hline Povolotskiy et al. ${ }^{26}$ & RCT & Non SCC & 1,595 & 673 & 922 & 59 & $54 / 46$ & 60 \\
\hline
\end{tabular}

(RCT: randomized clinical trial, SCC: squamous cell carcinoma, M: male, F: female)

Balamurugan Rajendran: Surgical outcomes of endoscopic versus open resection for the management of sinonasal malignancies. J Korean Assoc Oral Maxillofac Surg 2020 
patient with open surgical resection $(P=0.20)$.(Table 2$)$

\section{Recurrence}

Farquhar et al. ${ }^{15}$ observed recurrence in 16 patients with endoscopic resection and 13 patients with open resection $(P=0.058)$. Hagemann et al. ${ }^{16}$ observed recurrence in 57 patients for the endoscopic approach and in 52 patients for the open resection approach $(P=0.490)$. Fu et al. ${ }^{18}$ identified recurrence in 14 patients and 7 patients for endoscopic and open surgical resection $(P=0.21)$, respectively. Saedi et al. ${ }^{19}$ observed recurrence in 59 and 58 patients with endoscopic resection and open resection $(P=0.168)$, respectively, while Huang et al. ${ }^{20}$ observed 66 patients recurrence for both endoscopic and open resection $(P=0.359)$.(Table 2$)$

\section{Overall survival rate}

Naunheim et al. ${ }^{12}$ observed a 5-year survival rate of $82 \%$ in both the endoscopic and open resection approaches $(P=0.14)$. Farquhar et al. ${ }^{15}$ reported a 3-year survival rate of $91 \%$ and $76 \%$ for endoscopic and open resection $(P=0.135)$, respectively. Hagemann et al. ${ }^{16}$ reported a 5-year survival rate of $76 \%$ and $59 \%$ for endoscopic and open surgical resection $(P=0.001)$, respectively. Finally, Saedi et al. ${ }^{19}$ reported an overall survival rate of 2 years of $34 \%$ with endoscopic resection and $44 \%$ with open resection $(P=0.13)$.(Table 2$)$

\section{Discussion}

The purpose of this review paper is to systematically compare two different treatment modalities, endoscopic resection and open surgical resection, in terms of postoperative outcome variables such as positive margins, length of hospital stay, complication rates, recurrence rate and overall survival rate in the management of sinonasal malignancies.

Patients with sinonasal malignancies generally present with symptoms of unilateral nasal bleeding and obstruction of the nose ${ }^{1}$. In the past decades, the use of endoscopic surgeries in the sinonasal region was limited and predominantly preferred in cases with inflammatory nasal masses. The scope of resection through an endoscopic approach has widely been increased and various advanced methodologies have been implemented in the English literature ${ }^{21,22}$. The potential benefits of endoscopic resection are the elimination of facial scars and deformities caused by the open resection approach, short hospital stay, minimal trauma and cost effectiveness. However, endoscopic surgery has many limitations such as not being appropriate in cases with high volumes of tumor mass, which eventually results in high recurrence and a low survival rate postoperatively compared to open surgical resection ${ }^{23-25}$.

\section{Positive margins}

Hagemann et al. ${ }^{16}$ suggested that open surgical resection is the gold standard method for obtaining negative margins compared to endoscopic resection. However, Arnold et al. ${ }^{14}$ reported insignificant differences in the percentage of patients with positive margins between endoscopic resection and open resection surgeries, similar association to the results of the current paper and Farquhar et al. ${ }^{15}(P>0.05)$. Kilic et $\mathrm{al}^{4}$ reported that malignant tumors at stage IV B were treated with endoscopic approach. One probable explanation was that the surgeon would have been a skilled and experienced endoscopic surgeon. However, the authors did not verify this hypothesis as they did not indicate the number of patients treated by each surgeon. Another potential reason was that the surgeon may have mostly preferred a less invasive surgery since obtaining negative margins in advanced tumors is unlikely. This hypothesis is supported by the fact that even though the positive margins are comparable between endoscopic and open surgeries, the rate of positive margins was significantly greater in stage IV B patients who underwent endoscopic resection (endoscopic: $78.9 \%$, open resection: $53.3 \%, P=0.045)$.

\section{Length of hospital stay}

Farquhar et al. ${ }^{15}$ and Fu et al. ${ }^{18}$ observed a shorter hospital stay with endoscopic surgery. The results of the above study agree with the current paper, as well as with Naunheim et al. ${ }^{12}$, Mortuaire et al. ${ }^{17}$, and Hagemann et al. ${ }^{16}$. The average length of hospital stay ranges from 3.0 to 4.7 days for endoscopic resection and 5.7 to 11.5 days for open resection. The reduction in hospital stay may be attributed to reduced costs, decreased postoperative complication rates, and readmission rates in sinonasal surgery ${ }^{26}$. Thus, the length of stay should be taken into consideration when deciding between endoscopic and open approaches for sinonasal malignancies.

\section{Complication rates}

Any surgical procedure can present with complications postoperatively, however the rates of complication according 
to surgery remains unclear. Naunheim et al. ${ }^{12}$ observed high rates of complication with open resection approach, and the occurrence of CSF leak was greater in cases with the endoscopic approach, showing similar correlations with $\mathrm{Fu}$ et al. ${ }^{18}$. In 2016, Hagemann et al. ${ }^{16}$ performed a meta-analysis by comparing the surgical outcomes of the endoscopic and open resection approaches. Here, the authors reported that the outcomes for the endoscopic approach were similar to or greater than those for the open resection approach. Arnold et al. ${ }^{14}$ reported that the complication rates were significantly lower in the endoscopic approach (60\%) than in the open resection approach $(78 \%)$, which agreed with Mortuaire et al. ${ }^{17}$. As found in the English literature ${ }^{18}$, the overall complication rates between the endoscopic and open approaches range from 3\% to $26 \%$ and $15 \%$ to $53 \%$, respectively. The CSF leak rates were $3 \%$ to $12 \%$ for the endoscopic approach and $4 \%$ to $10 \%$ for the open approach.

\section{Recurrence rate}

In the current paper, the rate of recurrence was low in open surgical resection compared to the endoscopic approach $(P>0.05)$. The above results agreed with Saedi et al. ${ }^{19}$, wherein the authors reported a recurrence rate of 58 patients with open resection and 59 patients with endoscopic resection $(P=0.168)$. Moreover, the authors found no significant findings in the time period between the treatment procedure and recurrence. Hanna et al. ${ }^{27}$ observed $15 \%$ recurrence in 120 patients, where 93 patients were treated with endoscopic resection and 27 patients were treated with open resection, finding insignificant differences between these groups $(P>0.05)$.

\section{Overall survival rate}

The overall survival rate was greater in endoscopic resection compared to open resection $(P>0.05)$, which was a similar result to that found by Saedi et al. ${ }^{19}$. Here, the authors described a survival rate of 24 and 15 months for endoscopic resection, and 28 and 17 months for open resection, with insignificant differences found between endoscopic and open resection surgery $(P=0.13)$. Hagemann et al. ${ }^{16}$ reported 5-year survival rates of $87.5 \%$ in endoscopic resection and $84.6 \%$ in open resection for small tumors (T1 and T2) and 10-year survival rates of $52 \%$ in endoscopic resection and $33 \%$ in open resection for T4 tumors. Nicolai et al. ${ }^{28}$ observed a 5 -year survival rate of $91.4 \%$ and $58.8 \%$ for the endoscopic and open resection approaches, respectively. In contrast, Farquhar et al. ${ }^{15}$ reported a 3-year survival rate for open resection of $86 \%$, while that for the endoscopic resection approach was $74 \%$.

\section{Limitations}

The current review has a few limitations:

1. The randomized controlled trial comparing the surgical outcomes between the endoscopic and open resection approaches was limited to studies in English.

2. Each approach uses a different technique to access the malignancies of the sinonasal region, which influences the surgical outcome, e.g., positive margins. Further studies should be encouraged to provide a detailed description of the surgical outcomes.

\section{Conclusion}

The overall surgical outcomes between endoscopic resection and open surgical resection for the management of sinonasal malignancies cannot be concluded from the studies and results described in the English literature. Though both approaches have comparable advantages and disadvantages, preoperative evaluation of cases based on the primary site, age of the patient, gender, tumor size, American Joint Committee on Cancer (AJCC) staging, and histologic grading is needed for determining the right treatment method, which can benefit patients by providing lower morbidity rates postoperatively.

\section{Author's Contributions}

Literature search, data collection, data analysis, data interpretation, manuscript writing was contributed by B.R.

\section{Conflict of Interest}

No potential conflict of interest relevant to this article was reported.

\section{References}

1. Yavuz HB, Aslıer M, Demir UL, Kasapoğlu F. Endoscopic surgery for sinonasal cancer: Uludağ experience. Eur J Rhinol Allergy 2019;2:75-8.

2. Osguthorpe JD, Richardson M. Frontal sinus malignancies. Otolaryngol Clin North Am 2001;34:269-81. https://doi.org/10.1016/ s0030-6665(05)70311-x 
3. Kilic S, Shukla PA, Marchiano EJ, Patel RH, Baredes S, Liu JK, et al. Malignant primary neoplasms of the nasal cavity and paranasal sinus. Curr Otorhinolaryngol Rep 2016;4:249-58. https://doi. org/10.1007/s40136-016-0134-0

4. Kilic S, Kilic SS, Baredes S, Chan Woo Park R, Mahmoud O, Suh $\mathrm{JD}$, et al. Comparison of endoscopic and open resection of sinonasal squamous cell carcinoma: a propensity score-matched analysis of 652 patients. Int Forum Allergy Rhinol 2018;8:421-34. https:// doi.org/10.1002/alr.22040

5. Kilic S, Kilic SS, Baredes S, Liu JK, Eloy JA. Survival, morbidity, and quality-of-life outcomes for sinonasal and ventral skull base malignancies. Otolaryngol Clin North Am 2017;50:467-80. https:// doi.org/10.1016/j.otc.2016.12.018

6. Lee CH, Hur DG, Roh HJ, Rha KS, Jin HR, Rhee CS, et al. Survival rates of sinonasal squamous cell carcinoma with the new AJCC staging system. Arch Otolaryngol Head Neck Surg 2007;133:1314. https://doi.org/10.1001/archotol.133.2.131

7. Ansa B, Goodman M, Ward K, Kono SA, Owonikoko TK, Higgins $\mathrm{K}$, et al. Paranasal sinus squamous cell carcinoma incidence and survival based on surveillance, epidemiology, and end results data, 1973 to 2009. Cancer 2013;119:2602-10. https://doi.org/10.1002/ cncr.28108

8. Ketcham AS, Wilkins RH, Vanburen JM, Smith RR. A combined intracranial facial approach to the paranasal sinuses. Am J Surg 1963;106:698-703. https://doi.org/10.1016/0002-9610(63)90387-8

9. Abu-Ghanem S, Fliss DM. Surgical approaches to resection of anterior skull base and paranasal sinuses tumors. Balkan Med J 2013;30:136-41. https://doi.org/10.5152/balkanmedj.2013.9112

10. Patel SG, Singh B, Polluri A, Bridger PG, Cantu G, Cheesman AD, et al. Craniofacial surgery for malignant skull base tumors: report of an international collaborative study. Cancer 2003;98:1179-87. https://doi.org/10.1002/cncr.11630

11. Ganly I, Patel SG, Singh B, Kraus DH, Bridger PG, Cantu G, et al. Complications of craniofacial resection for malignant tumors of the skull base: report of an international collaborative study. Head Neck 2005;27:445-51. https://doi.org/10.1002/hed.20166

12. Naunheim MR, Goyal N, Dedmon MM, Chambers KJ, Sedaghat $\mathrm{AR}$, Bleier BS, et al. An algorithm for surgical approach to the anterior skull base. J Neurol Surg B Skull Base 2016;77:364-70. https://doi.org/10.1055/s-0036-1580598

13. Wood JW, Eloy JA, Vivero RJ, Sargi Z, Civantos FJ, Weed DT, et al. Efficacy of transnasal endoscopic resection for malignant anterior skull-base tumors. Int Forum Allergy Rhinol 2012;2:487-95. https://doi.org/10.1002/alr.21062

14. Arnold A, Ziglinas P, Ochs K, Alter N, Geretschläger A, Lädrach $\mathrm{K}$, et al. Therapy options and long-term results of sinonasal malignancies. Oral Oncol 2012;48:1031-7. https://doi.org/10.1016/ j.oraloncology.2012.04.005

15. Farquhar D, Kim L, Worrall D, Chiu A, Lee JY, Khalili S, et al. Propensity score analysis of endoscopic and open approaches to malignant paranasal and anterior skull base tumor outcomes. Laryngoscope 2016;126:1724-9. https://doi.org/10.1002/lary.25885

16. Hagemann J, Roesner J, Helling S, Jacobi C, Doescher J, Engelbarts $\mathrm{M}$, et al. Long-term outcome for open and endoscopically resected sinonasal tumors. Otolaryngol Head Neck Surg 2019;160:862-9. https://doi.org/10.1177/0194599818815881
17. Mortuaire G, Leroy X, Vandenhende-Szymanski C, Chevalier D, Thisse AS. Comparison of endoscopic and external resections for sinonasal instestinal-type adenocarcinoma. Eur Arch Otorhinolaryngol 2016;273:4343-50. https://doi.org/10.1007/s00405-0164181-4

18. Fu TS, Monteiro E, Witterick I, Vescan A, Zadeh G, Gentili F, et al. Costs and perioperative outcomes associated with open versus endoscopic resection of sinonasal malignancies with skull base involvement. J Neurol Surg B Skull Base 2017;78:430-40. https:// doi.org/10.1055/s-0037-1603907

19. Saedi B, Aghili M, Motiee M, Valadkhani S, Niazi AB, Safavi A. Surgical outcomes of malignant sinonasal tumours: open versus endoscopic surgical approaches. J Laryngol Otol 2014;128:784-90. https://doi.org/10.1017/S0022215114001583

20. Huang Y, Qiu QH, Zhang SX. Endoscopic surgery for primary sinonasal malignancies: treatment outcomes and prognostic factors. Ear Nose Throat J 2018;97:E24-30.

21. Banhiran W, Casiano RR. Endoscopic sinus surgery for benign and malignant nasal and sinus neoplasm. Curr Opin Otolaryngol Head Neck Surg 2005;13:50-4. https://doi.org/10.1097/00020840200502000-00012

22. Buchmann L, Larsen C, Pollack A, Tawfik O, Sykes K, Hoover LA. Endoscopic techniques in resection of anterior skull base/paranasal sinus malignancies. Laryngoscope 2006;116:1749-54. https:// doi.org/10.1097/01.mlg.0000233528.99562.c2

23. Eviatar E, Vaiman M, Shlamkovitch N, Segal S, Kessler A, Katzenell U. Removal of sinonasal tumors by the endonasal endoscopic approach. Isr Med Assoc J 2004;6:346-9.

24. Su SY, Kupferman ME, DeMonte F, Levine NB, Raza SM, Hanna EY. Endoscopic resection of sinonasal cancers. Curr Oncol Rep 2014;16:369. https://doi.org/10.1007/s11912-013-0369-6

25. Wellman BJ, Traynelis VC, McCulloch TM, Funk GF, Menezes AH, Hoffman HT. Midline anterior craniofacial approach for malignancy: results of en bloc versus piecemeal resections. Skull Base Surg 1999;9:41-6. https://doi.org/10.1055/s-2008-1058171

26. Povolotskiy R, Farber NI, Bavier RD, Cerasiello SY, Eloy JA, Hsueh WD. Endoscopic versus open resection of nonsquamous cell carcinoma sinonasal malignancies. Laryngoscope 2020;130:1872-6. https://doi.org/10.1002/lary.28270

27. Hanna E, DeMonte F, Ibrahim S, Roberts D, Levine N, Kupferman M. Endoscopic resection of sinonasal cancers with and without craniotomy: oncologic results. Arch Otolaryngol Head Neck Surg 2009;135:1219-24. https://doi.org/10.1001/archoto.2009.173

28. Nicolai $\mathrm{P}$, Battaglia $\mathrm{P}$, Bignami $\mathrm{M}$, Bolzoni Villaret $\mathrm{A}$, Delù $\mathrm{G}$, Khrais T, et al. Endoscopic surgery for malignant tumors of the sinonasal tract and adjacent skull base: a 10-year experience. Am J Rhinol 2008;22:308-16. https://doi.org/10.2500/ajr.2008.22.3170

How to cite this article: Rajendran B. Surgical outcomes of endoscopic versus open resection for the management of sinonasal malignancies. J Korean Assoc Oral Maxillofac Surg 2020;46:373378. https://doi.org/10.5125/jkaoms.2020.46.6.373 